\title{
Effect of superdisintegrants on formulation of taste masked fast disintegrating Ciprofloxacin tablets
}

\author{
*Nilesh Jain, Suman Mandal, Jitendra Banweer, Surendra Jain \\ Sagar Institute of Research and Technology-Pharmacy, Ayodhya Bypass Road, Bhopal, M.P. India - 462041
}

\begin{abstract}
The present investigation deals with the formulation of taste masked fast disintegrating tablets of Ciprofloxacin that disintegrate in the oral cavity upon contact with saliva and thereby improve therapeutic efficacy. Ciprofloxacin is a synthetic chemotherapeutic antibiotic of the fluoroquinolone drug class. It is a second-generation fluoroquinolone antibacterial that kills bacteria by interfering with the enzymes that cause DNA to rewind after being copied, which stops synthesis of DNA and protein. It may also be used to prevent or slow anthrax after exposure. The influence of superdisintegrants, crospovidone and sodium starch glycolate on disintegration time, wetting time and water absorption ratio were studied. Tablets were evaluation for weight and thickness variation, disintegration time, drug content, in vitro dissolution, wetting time and water absorption ratio. The in vitro disintegration time of the best fast disintegration tablets was found to be within 36 seconds. Tablets containing crospovidone (40\%) exhibits quick disintegration time than tablets containing sodium starch glycolate. The fast disintegrating tablets of ciprofloxacin with shorter disintegration time, acceptable taste and sufficient hardness could be prepared using crospovidone and other excipients at optimum concentration.
\end{abstract}

Key Words: ciprofloxacin, sodium starch glycolate, crospovidone, superdisintegrants, taste mask, fast disintegrating tablet.

\section{INTRODUCTION}

Most pharmaceutical dosage forms for oral administration are formulated for direct ingestion, for chewing, for prior dispersion and/or dissolution in water; some of them are absorbed in mouth (sublingual or buccal tablets) (Birudaraj et al., 2005). Elderly individuals have difficulty in swallowing when prescribed in conventional tablet and capsule form (Rajitha et al., 2009, Chang et al., 2000, Yeola et al., 2000). The problem of swallowing is also evident in pediatrics, psychiatric as well as traveling patients who may not have ready access to water. The rapidly disintegrating tablet in mouth oro-dispersible tablets overcome all the above problems and thus offer an alternate form of oral medication, which provide patients with a more convenient means of taking their Addition of super disintegrating agent in the formulation is one of the approaches to for-

\footnotetext{
*Corresponding Author:

Nilesh Jain, Associate Professor

Sagar Institute of Research and Technology-Pharmacy

Bypass Road, Bhopal (M.P.) - 462036 (India)

E-mail: nilujain01@yahoo.co.in

Contact No.: +919425074520
}

mulate oral dispersible tablets. Orally disintegrating tablets contain wide variety of pharmaceutical active ingredients covering many therapeutic categories. The time for disintegration of orally disintegrating tablets are generally considered less than 1 minute (IP, 2007). Orally disintegrating tablets are characterized by high porosity, low density and low hardness. When administered, an in-situ suspension is created in the oral cavity as the tablet disintegrates and is subsequently swallowed. Solid dosage forms are popular because of ease of administration, accurate dosage, self medication, pain avoidance and most importantly patient compliance (IP, 2007). Keeping in view the advantages of this delivery system, in the present study attempts were made to formulate taste masked orally disintegrating tablets of ciprofloxacin which is used as an antibiotic taste masking of ciprofloxacin was done by keeping it with sodium saccharin and different superdisintegrating agent. 


\section{MATERIALS AND METHODS}

\section{Materials}

Ciprofloxacin was gifted from Dr. Reddy's Laboratories (Hyderabad, India). Crospovidone, sodium starch glycolate were obtained from Merck LTD (Mumbai). Magnesium stearate and all other ingredients used were of analytical grade.

\section{Super Disintigrants}

\section{Crospovidone}

It is a white, free flowing, compressible powder; a synthetic homopolymer of cross-linked $\mathrm{N}$-vinyl pyrrolidinone. It is completely insoluble in water, acids, alkalis and all organic solvents. Hygroscopic in nature, swells rapidly in water, rapidly disperse in water, but does not gel even after prolonged exposure (IP, 2007).

Sodium Starch Glycolate

It is sodium salt of carboxymethyl ether of starch. It is white to off white tasteless, odourless, relatively free flowing powder, insoluble in organic solvent (IP, 2007).

\section{Preparation of fast disintegrating tablets of ciprof- loxacin by Kneading technique}

Required quantity of ciprofloxacin was weighed and sifted through \# 40 ASTM SS sieve. Drug was mixed with the crospovidone and starch glycolate in different ration (Table 1) with the above powder base with sifted avicel, and other exicipients by tumbling. All the ingredients were mixed thoroughly for not less than 5 minutes and until to get uniform mixed powder. Finally, the lubricated granules were compressed on rotary tablet machine (Sastr et al., 2000; Ito et al., 1996; Dobetti, 2001).

\section{Evaluation of granules}

The angle of repose was measured by using funnel method (Kuchekar et al., 2003) which indicates the flow ability of the granules. Loose bulk density (LBD) and tapped bulk density (TBD) (Liberman and Lachman, 2006) were measured using the formula-

$$
\begin{aligned}
\mathrm{LBD} & =\frac{\text { weig ht of the powder }}{\text { volume of the packing }} \\
\mathrm{TBD} & =\frac{\text { weig ht of the powder }}{\text { tapped volume of the packing }}
\end{aligned}
$$

Compressibility index (Shah and Rampadhan, 1997) of the granules was determined by using the formula-CI $(\%)=\left[\left(\mathrm{TBD}-\frac{\mathrm{LBD}}{\mathrm{TBD}}\right)\right] \times 100$
Table 1: Composition of Different Batches of Fast Disintegrating Cipro Tablets.

\begin{tabular}{lcccccc}
\hline \multirow{2}{*}{ Ingredients } & \multicolumn{7}{c}{ Amount (mg) } \\
\cline { 2 - 7 } & F-1 & F-2 & F-3 & F-4 & F-5 & F-6 \\
\hline Ciprofloxacin & 150 & 150 & 150 & 150 & 150 & 150 \\
Avicel & 60 & 60 & 60 & 60 & 60 & 60 \\
Lactose & 18 & 18 & 18 & 18 & 18 & 18 \\
Starch powder & 50 & 50 & 50 & 50 & 50 & 50 \\
Crospovidone & 40 & 50 & 60 & - & - & - \\
Sodium Starch Gly- & & & & 40 & 50 & 60 \\
colate & - & - & - & & & \\
Sodium Saccharin & 20 & 20 & 20 & 20 & 20 & 20 \\
Vanillin & 20 & 20 & 20 & 20 & 20 & 20 \\
Magnesium Stearate & 25 & 25 & 25 & 25 & 25 & 25 \\
Coloring agent & 25 & 25 & 25 & 25 & 25 & 25 \\
\hline
\end{tabular}

\section{Evaluation of the tablets}

All prepared matrix tablets were evaluated for its uniformity of weight, hardness, friability and thickness according to official methods (Aulton and Well, 2000).

\section{Hardness}

The crushing strength of the tablets was measured using a Monsanto hardness tester. Three tablets from each formulation batch were tested randomly and the average reading noted.

\section{Friability}

Ten tablets were weighed and placed in a Roche friabilator (Electrolab USP friabilator) and the equipment was rotated at $25 \mathrm{rpm}$ for $4 \mathrm{~min}$. The tablets were taken out, dedusted and reweighed. The percentage friability of the tablets was calculated as per the following formula-

Percentage friability $=\frac{\text { Initial } \text { weight }- \text { Final weight }}{\text { Initial weight }} \times 100$

\section{Weight Variation}

Randomly, twenty tablets were selected after compression and the mean weight was determined. None of the tablets deviated from the average weight by more than $\pm 7.5 \%$ (USP XX).

\section{Drug content}

Twenty tablets were weighed and powdered by using mortar and pestle. An amount of the powder equivalent to $150 \mathrm{mg}$ of ciprofloxacin was dissolved in $100 \mathrm{ml}$ of phosphate buffer $\mathrm{pH} 6.8$, filtered, diluted suitably and analyzed for drug content at 
Table 2: Data for Blend Evaluation of Formulation F-1 to F-6.

\begin{tabular}{lllllll}
\hline \multirow{2}{*}{\multicolumn{1}{c}{ Parameter }} & \multicolumn{5}{c}{ Formulation code } \\
\cline { 2 - 7 } & F-1 & F-2 & F-3 & F-4 & F-5 & F-6 \\
\hline Angle of repose $\left(^{\circ}\right)$ & $24.33 \pm 0.91$ & $28.99 \pm 0.33$ & $23.33 \pm 0.11$ & $24.13 \pm 0.23$ & $24.30 \pm 0.49$ & $25.38 \pm 0.19$ \\
Loose bulk density $(\mathrm{LBD})(\mathrm{g} / \mathrm{ml})$ & $0.278 \pm 0.20$ & $0.521 \pm 0.3$ & $0.321 \pm 0.72$ & $0.342 \pm 0.21$ & $0.376 \pm 0.69$ & $0.421 \pm 0.64$ \\
Taped bulk density(TBD) $(\mathrm{g} / \mathrm{ml})$ & $0.346 \pm 0.17$ & $0.589 \pm 0.24$ & $0.434 \pm 0.90$ & $0.463 \pm 0.88$ & $0.572 \pm 0.22$ & $0.482 \pm 0.83$ \\
Compressibility index $(\%)$ & $14.66 \pm 0.33$ & $13.23 \pm 38$ & $15.21 \pm 19$ & $14.56 \mathrm{v} 0.22$ & $13.28 \pm 0.39$ & $13,98 \pm 0.52$ \\
\hline
\end{tabular}

${ }^{*}$ Results are presented as Mean \pm S.D

257nm using UV-Visible spectrophotometer (UV 160 Shimadzu, Japan).

\section{Wetting time}

A piece of tissue paper $(12 \mathrm{~cm} \times 10.75 \mathrm{~cm})$ folded twice was placed in a Petri dish (Internal Diameter $=9 \mathrm{~cm}$ ) containing $9 \mathrm{ml}$ of buffer solution simulating saliva $\mathrm{pH} 7.4$, which had the following composition, $\mathrm{NaCl}(0.126 \mathrm{~g}), \mathrm{KCl}(0.964 \mathrm{~g}), \mathrm{KSCN}$ $(0.189 \mathrm{~g}), \mathrm{KH}_{2} \mathrm{PO}_{4}(0.655 \mathrm{~g})$ and urea $(0.200 \mathrm{~g})$ in 1Litre of distilled water. A tablet was placed on the paper and the time taken for complete wetting was noted. Three tablets from each formulation were randomly selected and the average wetting time was noted.

\section{Water absorption ratio $(R)$}

The weight of the tablet prior to placement in the petri dish was noted $(w b)$ utilizing a Shimadzu digital balance. The wetted tablet was removed and reweighed $(w a)$. Water absorption ratio, $R$, was then determined according to the following equation.

$R=\frac{w a-w b}{w a w b} \times 100$

Here $w b$ and $w a$ were tablet weights before and after water absorption, respectively.

\section{In Vitro dispersion time}

In vitro Dispersion time was measured by dropping a tablet in $10 \mathrm{ml}$ measuring cylinder containing $6 \mathrm{ml}$ of $0.1 \mathrm{~N}$ hydrochloric acid.

\section{In Vitro disintegration time}

$10 \mathrm{ml}$ of water at $25^{\circ} \mathrm{C}$ was placed in a petri dish of $10 \mathrm{~cm}$ diameter. The tablet was then carefully positioned in the center of the petri dish and the time required for the tablet to completely disintegrate into fine particles was noted.

\section{In Vitro drug release studies}

In vitro drug release studies of all the formulations were carried out using tablet dissolution test apparatus (USP XXII type II Labindia, Mumbai, India) at $50 \mathrm{rpm}$. Phosphate buffer $\mathrm{pH} 6.8$ was used as the dissolution media with temperature maintained at $37 \pm 1^{\circ} \mathrm{C}$. Samples were withdrawn at different intervals, diluted suitably and analyzed at $257 \mathrm{~nm}$ for cumulative drug release using an ultraviolet visible spectrophotometer (Shimadzu 1700 series). The study was performed in triplicate.

\section{Stability studies}

Short term stability studies on the optimum formu-

Table 3: Thickness, Hardness, Friability, Drug Content, Weight Variation, Wetting Time, Water Absorption Ratio, invitro Dispersion Time, in-vitro Disintegration Time of Ciprofloxacin Fast Disintegrating Tablets.

\begin{tabular}{|c|c|c|c|c|c|c|}
\hline \multirow{2}{*}{ Parameter } & \multicolumn{6}{|c|}{ Formulation code } \\
\hline & F-1 & F-2 & F-3 & F-4 & F-5 & F-6 \\
\hline Hardness* & $3.42 \pm 0.36$ & $3.8 \pm 1.4$ & $3.03 \pm 1.19$ & $3.2 \pm 1.33$ & $3.81 \pm 1.8$ & $3.38 \pm 1.23$ \\
\hline Thickness* & $2.01 \pm 0.18$ & $2.10 \pm 0.49$ & $2.11 \pm 0.22$ & $2.51 \pm 1.72$ & $2.24 \pm 0.17$ & $2.43 \pm 1.21$ \\
\hline Friability & 0.398 & 0.430 & 0.532 & 0.521 & 0.562 & $0 . .432$ \\
\hline Drug content* & $96.66 \pm 0.33$ & $99.1 \pm 0.08$ & $97.21 \pm 19$ & $96.56 \pm 0.22$ & $97.1 \pm 0.71$ & $96.98 \pm 0.52$ \\
\hline Weight variation & 201.34 & 200.48 & 203.42 & 202.54 & 203.45 & 204.32 \\
\hline Wetting time & 47 & 30 & 43 & 41 & 31 & 45 \\
\hline Water absorption ratio & 92 & 94 & 91 & 92 & 95 & 93 \\
\hline In-vitro dispersion time (sec)* & 63 & 67 & 66 & 64 & 65 & 63 \\
\hline In-vitro disintegrating time (sec)* & 39 & 36 & 40 & 41 & 38 & 40 \\
\hline
\end{tabular}




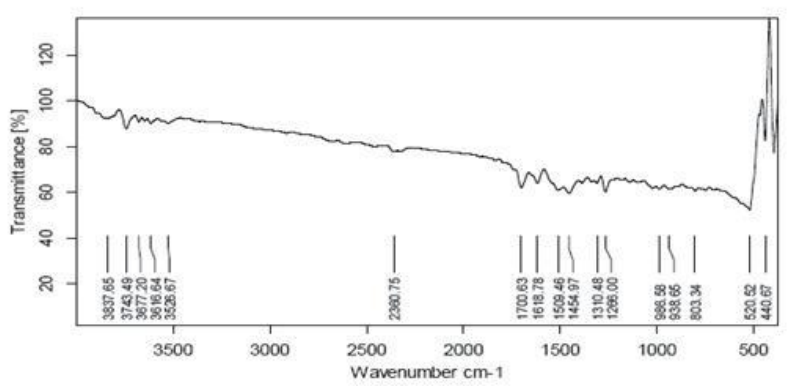

(A)

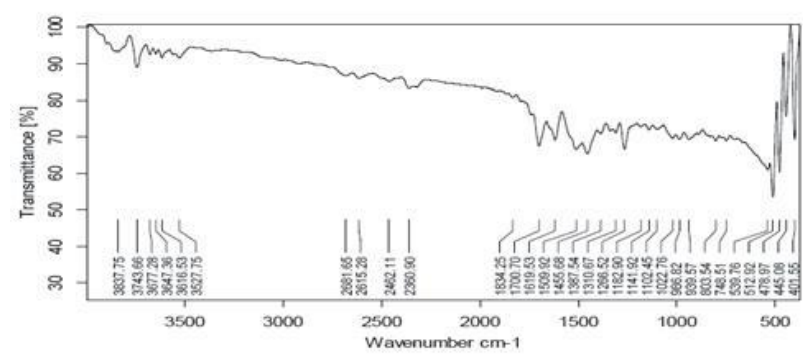

(B)

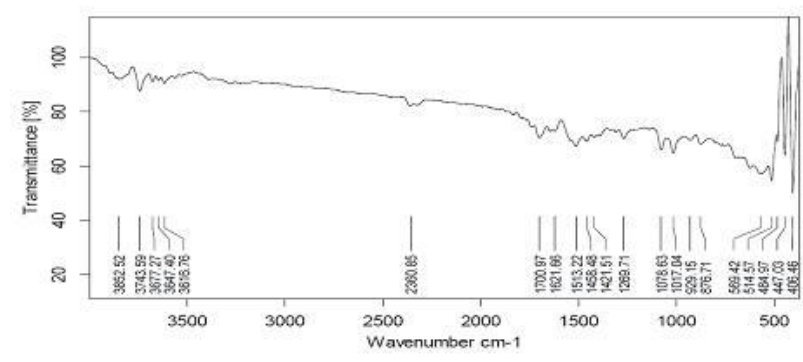

(C)

Figure 1: Fourier transform infra red (FTIR) spectra of (A) Ciprofloxacin (B) Ciprofloxacin + Crospovidone (C) Ciprofloxacin +SSG.

lation (F-2, F-5) were carried out by storing the tablets (in amber colored rubber stoppered vials) at $40^{\circ} \mathrm{C} / 75 \% \mathrm{RH}$ for 3 weeks. At every 1 week intervals, the tablets were examined for physical changes, properties, drug content and in vitro release studies (Chang and Robinson, 2006, Marshall et al., 2000).

\section{RESULTS AND DISCUSSION}

The supplied drug passed the various tests of identification and analysis. The pure drug ciprofloxacin and the solid admixture of drug and various excipients used in the preparation of fast dispersible tablet formulations were characterized by FT-IR spectroscopy to know the compatibility (Figure 1).

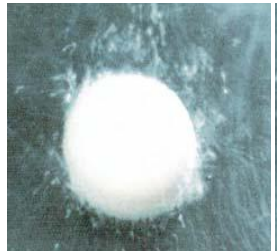

$5 \mathrm{sec}$

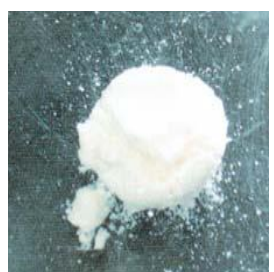

$20 \mathrm{sec}$

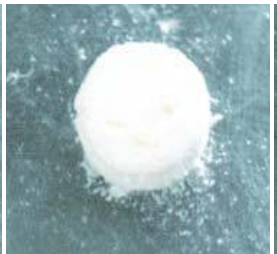

$10 \mathrm{sec}$

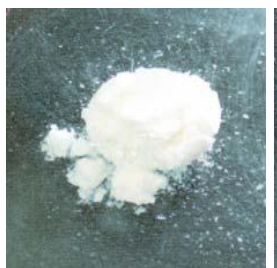

$25 \mathrm{sec}$

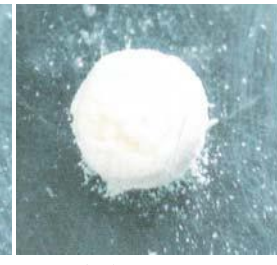

$15 \mathrm{sec}$

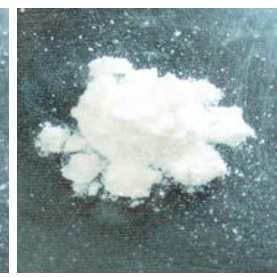

$36 \mathrm{sec}$
Figure 2: Disintegration process of tablet (F-2).

The FT-IR study did not show any possibility of interaction between ciprofloxacin and superdisintegrants used in the fast dispersible tablets.

Since the flow properties of the powder mixture are important for the uniformity of the mass of the tablets, the flow of the powder mixture was analyzed before compression of the tablets. The results of angle of repose and compressibility index (\%) ranged from $(23.33 \pm 0.11$ to $28.99 \pm 0.33)$ and $(13.23 \pm 38$ to $15.21 \pm 19)$, respectively. The loose bulk density and tapped bulk density were ranged from $(0.278 \pm 0.20$ to $0.521 \pm 0.3)$ and $(0.346 \pm 0.17$ to $0.589 \pm 0.24)$, respectively. The lowest compressibility index is 5-15\% which indicates excellent flow properties (Table 2).

The physical properties of different batches of fast dissolving tablets are given in table 3 . Tablet mean thickness was almost uniform in all the formulations. The thickness varies between $2.01 \pm 0.18$ to $2.51 \pm 1.72 \mathrm{~mm}$. The prepared tablets in all the formulations possessed good mechanical strength with sufficient hardness in the range of $3.03 \pm 1.19$ to $3.81 \pm 1.8 \mathrm{~kg} / \mathrm{sq} . \mathrm{cm}$. Friability values below $1 \%$ were an indication of good mechanical resistance of the tablets. The weight variation in all the six formulations was found to be 199.71 to $202.19 \mathrm{mg}$, thus the tablets from each formulation passed weight variation test, as the \% weight variation was within the pharmacopoeial limits of $\pm 7.5 \%$ of the weight. The percentage drug content of all the tablets was found to be between $96.56 \pm 0.22$ to $99.1 \pm 0.08 \%$ of Ciprofloxacin which was within the acceptable limits. 


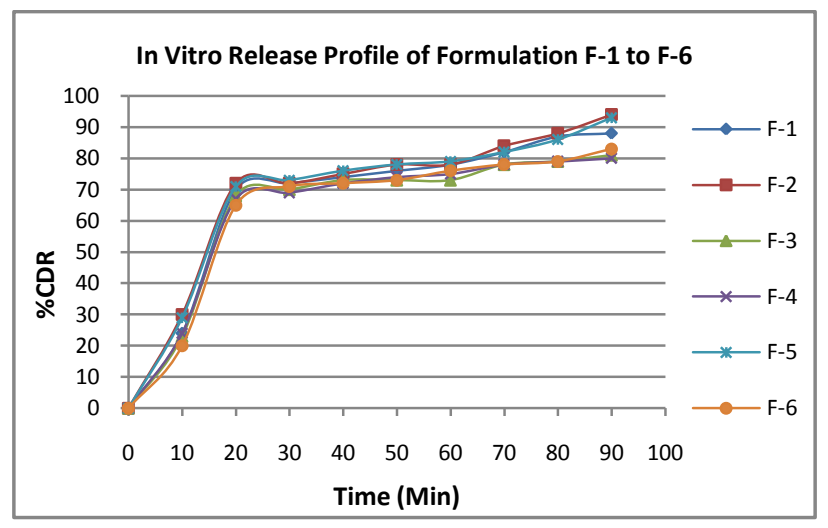

Figure 3: Comparison of in-vitro release profile of ciprofloxacin from formulations.

The wetting time for all the six formulations was performed in triplicate. The values lie between 23 to52 sec. In vitro dispersion is a special parameter in which the time taken by the tablet to produce complete dispersion is measured. The time for all the six formulations varied between 30 to $45 \mathrm{sec}$. Tablets were prepared with crospovidone F-1 to F-3 and with SSG F-4 to F-6. The wetting time, in vitro dispersion time of the tablets were also considerably reduced in tablets containing crospovidone which may be attributed due to the wicking type of disintegrants (crospovidone) formed thus facilitating the disintegrants to bring about faster disintegration. The water absorption ratio (\%) and in vitro disintegrating time (sec) were ranged from (91 to 97) and (36 to 41 ), respectively. The in vitro dissolution profile indicated faster and maximum drug release from formulation F-2 \& F-5 (Figure 2). In vitro drug release results of all the formulations were satisfactory (Figure 3).

Stability studies showed no significant change when compared with zero day of formulation (F-2 \& F-5). The disintegration times of tablets prepared with crospovidone were comparatively lower than that with sodium starch glycolate (Figure 3). The faster disintegration of these tablets may be attributed to the rapid capillary activity and pronounced hydration of crospovidone with little tendency to gel formation. Thus, these results suggest that the disintegration time can be decreased by using wicking type of disintegrants (crospovidone).

\section{CONCLUSION}

The oral disintegrating tablets of ciprofloxacin with sufficient mechanical strength, acceptable taste and smaller disintegration time were achieved employing suitable superdisintegrants and other excipients at optimum concentration. Stability studies revealed that there was no significant change in drug content and dissolution profile of oral disintegrating tablets. FTIR studies revealed that there was no shift in peaks, indicating there is no interaction between ciprofloxacin and other ingredients used. Among two superdisintegrants used, crospovidone showed better performance in disintegration time when compared to sodium starch glycolate. So the formulation of F-2 was found to be best among all other formulations, because it has exhibited faster wetting time, good taste and faster disintegration time when compared to all other formulations.

\section{ACKNOWLEDGEMENT}

The authors are thankful to the Dr. Surendra Jain, Director, Sagar institute of Research and Technology- Pharmacy, for providing necessary facilities to carry out this work.

\section{REFERENCES}

Aulton, M.E., Well, T.I. (2000). Pharmaceutics: The Sciences of Dosage form Design. New York: Churchill Livingstone; pp.424.

Birudaraj, R., Berner, B, Shen, S., Li, X. (2005). Buccal Permeation of Buspirone: Mechanistic Studies on Transport Pathways. Journal of Pharmaceutical Sciences. 68: 70-78. [DOI] PMid:15761931

Chang, R.K., Xiaodi, G., Burnside, B.A., Couch, R.A. (2000). Fast Dissolving Tablets. Pharm. Technol. 24(6): 52-58.

Chang, R., Robinson, J.R. (2006). Sustained Release From Tablets and Particles Through Coating, In : Libreman, H.A., Lachman, L. Schwartz, J.B. Pharmaceuticals Dosage form: Tablets, Marceel Dekker. Vol. 3, pp.199-302.

Cooper, J., Gunn, G. (1986). Powder Flow and Compaction, In; Tutorial Pharmacy. New Dehli: CBS Publisers and Distributers, pp.211-233.

Dobetti, L. (2000). Fast-Melting Tablets: Developments and Technologies. Pharm. Technol. Europe 12(9): 32-42.

Goodman \& Gilman's. (2001). The Pharmacological Basis of Therapeutics, New York: McGraw-Hill Publication. pp. 342. 
Liberman and Lachman. (2006). Pharmaceutical Dosage Forms: Tablets. Hardcover, Informa Healthcare. 1 [2], pp.195-245.

Indian Pharmacopoeia (2007). Government of India, The Controller of Publication New Delhi: 615, 663-665, 974, 1733.

Ito, A., Sugihara, M. (1996). Development of Oral Dosage Forms for Elderly Patients: Use of Ager as Base of Rapidly Disintegrating Oral Tablets. Chemical \& Pharmaceutical Bulletin. 11[44]: 2132-36. [DOI]

Kuchekar, B.S., Badhan, A.C., Mahajan, H.S. (2003). Mouth Dissolving Tablet: A Novel Drug Delivery System. Pharmaceutical Times. 35(6): 7-9.

Marshall, K., Lachman, N., Liberman, H.A. (2000). The Theory and Practice of Industrial Pharmacy. Mumbai : Varghese Publishing House; pp.66-69.

Rajitha, K., Shravan, K.Y., Adhukondalu, D., Ramesh, G., Rao, Y.M. (2009). Formulation and Evaluation of Orally Disintegrating Tablets of Buspirone. International Journal of Pharmaceutical Sciences and Nanotechnology. 1(4): 327-334.
Sastry, S.V., Nyshadham, J.R., Fix, J.A. (2000). Recent Technological Advances in Oral Drug Delivery - A Review. Pharmaceutical Science \& Technology Today. 3(4): 138-145. [DOI]

Shah, D., Shah, Y., Rampadhan, M. (1997). Development and Evaluation of Controlled Release Diltiazem Hydrochloride Micro Particlesusing Cross-Linked Polymer (Vinayl Alcohol). Drug Dev Ind Pharm. 23(6): 567-574. [DOI]

Swarbrik, J., Hillery, A.M., Andrew, W. (2001). Drug Delivery and Targeting: For Pharmacists and Pharmaceutical Scientists. CRC Press, pp.474.

Yeola, B.S., Pisal, S.S., Paradkar, A.R., Mahadik, K.R. (2000). New Drug Delivery Systems for elderly. Indian Drugs. 37 (7): 312-318. 